\title{
SPECIFICITY OF ANTIBODIES FOR T SITES AND F SITES OF STREPTOLYSIN O
}

\author{
K. C. Watson and E. J. C. KerR \\ Central Microbiological Laboratories, Western General Hospital, \\ Edinburgh EH4 $2 X U$
}

\begin{abstract}
Summary. Antistreptolysin antibody (ASO) inhibits haemolysis of erythrocytes coated with streptolysin O (SLO), but antistreptolysin activity may also be due to the presence in sera of peptide fragments of altered $\beta$ lipoproteins. SLO-mediated haemolysis results from activity of a molecular site (the $t$ site) distinct from that at which the SLO becomes attached to the cell (the $f$ site), and both sites might be expected to function antigenically. Absorption studies with SLO-coated latex particles, and with SLO-coated erythrocytes in the cold, provide evidence for the existence of both classes of antibody. Results also suggest explanations for the frequent observation of false-negative and false-positive latex tests.
\end{abstract}

\section{INTRODUCTION}

Studies by Alouf and Raynaud (1968) on haemolysis by streptolysin O indicate that this is a biphasic event brought about by the successive activity of two sites on the toxin molecule. In stage one, the lysin becomes attached to the cholesterol of the erythrocyte membrane by the f site. This event is temperature independent but thiol dependent, the bond being broken by sulphydryl reagents. Oxidised SLO fails to bind to membrane cholesterol and the presence of free cholesterol inhibits binding. Stage 2 -the actual haemolytic event-is initiated by a separate site on the toxin, the $t$ site. It is temperature dependent (maximal at about $37^{\circ} \mathrm{C}$ and absent at $0^{\circ} \mathrm{C}$ ) and is thiol independent. The nature of the molecular events initiated by the $t$ site is uncertain. Studies of inhibition of SLO by a variety of antisera led Alouf and Raynaud (1968) to predict that both sites may act as antigens. If so, antibody with specificity for either would inhibit haemolysis in the standard ASO test, the serum titre reflecting the component present in greater amount. However, formal proof of their existence is so far lacking.

A second mechanism of SLO inhibition exists and may give rise to false positive ASO haemolysis-inhibition tests. This is the presence in the serum of a factor derived from low-density $\beta$ lipoproteins and designated anti-streptolysin factor (ASF) by Watson and Kerr (1976). ASF activity can be generated in sera in which Staphylococcus aureus or Pseudomonas aeruginosa has been grown. High titres can be obtained in this way, and activity resides in peptide fragments of mol. wt 25000-100000, in 
which cholesterol is spatially orientated in such a way as to be capable of binding to $f$ sites of SLO (Watson and Kerr, 1975 and 1976).

In this investigation we have attempted to show that antibodies with $\mathrm{f}$-site or $\mathrm{t}$-site specificity are present in human sera obtained from patients infected with Streptococcus pyogenes (Lancefield group-A strains).

\section{MATERIALS AND METHODS}

Sera. These were separated from samples of clotted human blood and stored at $-20^{\circ} \mathrm{C}$ until required.

ASO tests. These were done by a microtitration modification of the standard method of Rantz and Randall (1945) in disposable plastic trays; 50\% haemolytic end-points were read visually with the aid of a magnifying viewer.

Latex-ASO tests. Commercially available kits were employed (Hoechst Laboratories Ltd, Middlesex). The principle of the procedure is that (1) sufficient SLO is added to serum to neutralise 200 Todd units of ASO activity; and (2) latex-SLO reagent is then added to the serum-SLO mixture on a slide. Any agglutination represents antibody in excess of 200 Todd units.

Removal of ASF from serum. ASF activity was precipitated out of serum in the $\beta$ lipoprotein fraction by adding dextran sulphate $10 \% \mathrm{w} / \mathrm{v}$ and $0.1 \mathrm{M} \mathrm{CaCl}_{2}$ according to the method of Burnstein and Samaille (1958).

Preparation of ASF. This was performed as described by Watson and Kerr (1976). Mixtures of horse serum and broth $(70: 30, \mathrm{v}: \mathrm{v})$ were made in 5. 0 -ml amounts; four drops of an 18 -h broth culture of Staphylococcus aureus NCTC7121 were added to each and the cultures agitated on a shaker at $37^{\circ} \mathrm{C}$ for $96 \mathrm{~h}$. ASF titres of the supernatant fluids ranged from 6000 to 25000 depending on the particular batch of horse serum.

Absorption of sera with SLO-latex. Sera with raised ASO titres were diluted 1 in 100 in $0.85 \%$ saline and then mixed in $0 \cdot 2-\mathrm{ml}$ amounts with equal volumes of SLO-latex particles and left at room temperature for $2 \mathrm{~h}$. Particles were removed by centrifugation and the absorption was repeated three times. ASO titres were then determined in the haemolytic assay. Haemagglutination noted in low dilutions of some high-titre ASO sera was also recorded. Control volumes of sera were adsorbed with uncoated latex particles.

Absorption of sera with $S L O$-coated erythrocytes at $0^{\circ} \mathrm{C}$. Advantage was taken of the ability of SLO to attach to erythrocyte-membrane cholesterol at $0^{\circ} \mathrm{C}$ without causing lysis. All reagents were cooled to $0^{\circ} \mathrm{C}$ in a carefully controlled refrigerated centrifuge. Human group-O Rh-negative cells were washed three times in cold $0.85 \%$ saline. After centrifugation, the packed cells were added in 1.0-ml volumes to 22 units of SLO (Wellcome Laboratories, Beckenham) dissolved in $10 \mathrm{ml}$ of distilled water. Distilled water was used because the dried product is hypertonic. Adsorption of SLO is almost instantaneous and the cells were again centrifuged after $5 \mathrm{~min}$. The SLO-coated packed cells were then used to absorb $1 \cdot 0-\mathrm{ml}$ volumes of positive ASO sera diluted to contain 256 Todd units $/ \mathrm{ml}$. After $4 \mathrm{~h}$ at $0^{\circ} \mathrm{C}$ the cells were again centrifuged and the supernatant fluids removed for retitration of ASO. In a number of cases the absorption process was repeated three times. The remaining cells were washed three times in the cold with $0.85 \%$ saline to remove all residual serum and then added to a final $0.5-\mathrm{ml}$ volume of saline and warmed to $37^{\circ} \mathrm{C}$. Control preparations of similar cells not coated with SLO were exposed to the same sera under identical conditions and treated in a similar manner. On warming these latter cells to $37^{\circ} \mathrm{C}$ rapid haemolysis occurred, showing that SLO was attached at $0^{\circ} \mathrm{C}$ and that $\mathrm{t}$-site activity was not impaired.

Immunofluorescence. Erythrocytes in microtitration-plate wells showing no haemolysis in the standard ASO haemolytic test were washed three times in phosphate buffered saline, $p \mathrm{H} 7 \cdot 6$, and then spread thinly on slides. They were air dried and exposed for $30 \mathrm{~min}$ to rabbit antihuman globulin conjugated with fluorescein isothiocyanate with specificity for both IgM and IgG antibodies. After washing in buffered saline the slides were examined with an incident light ultraviolet microscope (Leitz Ortholux). 


\section{RESULTS}

\section{Presence of t-site antibody}

The presence of antibody with t-site specificity is suggested by the following experimental procedures.

Absorption of serum with SLO-latex. A small percentage of sera in the standard haemolytic ASO test are noted to cause agglutination of erythrocytes in the lower serum dilutions. The results of repeated absorption of three such sera (nos 1,2 and 3) with SLO-latex are detailed in table I. The results obtained would be expected if there were insufficient antibody with $\mathrm{f}$-site specificity available to bind all $\mathrm{f}$ sites in the first stage of the test. This would allow residual SLO molecules to attach to red cells and, if already bound to t-site antibody, haemagglutination would occur. The haemagglutination titre would thus depend on the amount of t-site antibody and the number of SLO $\mathrm{f}$ sites free to bind to membrane cholesterol. The abolition of haemagglutination after absorption with SLO-latex suggests that SLO is attached to latex in a spatial configuration that leaves $t$ sites exposed. If the serum ASO titre is determined by f-site antibody no agglutination would be expected, as exemplified by sera 4 and 5 (table I). Because absorption with SLO latex also reduced the ASO titres in these two sera it would appear that both $f$ sites and $t$ sites are available on latex particles for antibody binding.

It is possible that other streptococcal antigens present in SLO preparations might coat erythrocytes, resulting in haemagglutination with antibody of appropriate specificity. If this was the case, however, we would expect haemagglutination to be seen quite often in ASO tests on sera from patients with group-A streptococcal infections; in fact it is a very uncommon observation and one likely to be noted only in laboratories performing large numbers of such tests.

Removal of ASF with dextran sulphate. Table II shows the effect, in three other sera with high ASO titres, of treatment with dextran sulphate on the titres of haemagglutination. The results can be interpreted as follows. The higher levels of haemagglutination noted with sera 6 and 7 after dextran precipitation would be expected if the sera

\section{TABLE I}

Titres of ASO and of haemagglutination, in the standard haemolytic ASO test, on selected sera* before and after absorption with SLO-latex

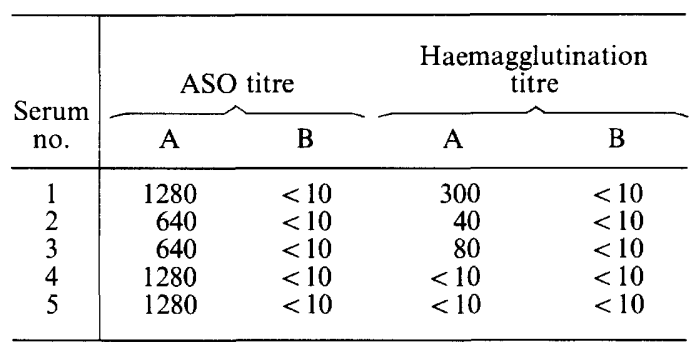

$A=$ titre before absorption with SLO-latex.

$\mathrm{B}=$ titre after absorption with SLO-latex.

* ASF had been removed from the sera by precipitation with dextran sulphate before these tests were performed. 
TABLE II

Haemagglutination titres before and after precipitation of ASF with dextran sulphate

\begin{tabular}{|c|c|c|c|c|}
\hline \multirow{2}{*}{$\begin{array}{l}\text { Serum } \\
\text { no. }\end{array}$} & \multicolumn{2}{|c|}{ ASO titre } & \multicolumn{2}{|c|}{ Haemagglutination } \\
\hline & A & B & A & B \\
\hline $\begin{array}{l}6 \\
7 \\
8\end{array}$ & $\begin{array}{r}1280 \\
640 \\
640\end{array}$ & $\begin{array}{r}1280 \\
640 \\
640\end{array}$ & $\begin{array}{r}40 \\
40 \\
0\end{array}$ & $\begin{array}{c}320 \\
160 \\
0\end{array}$ \\
\hline
\end{tabular}

$\mathrm{A}=$ titre before precipitation with dextran sulphate.

$\mathrm{B}=$ titre after precipitation with dextran sulphate.

contained little f-site antibody and only low levels of ASF. The available cholesterol on the peptide fragments of ASF would rapidly bind the f sites of SLO and so prevent the latter binding to erythrocyte-membrane cholesterol. Haemagglutination would occur when residual SLO not bound to ASF bound to cell membranes and reacted with $t$-site antibody. Removal of ASF with dextran would increase the amount of SLO capable of cell binding because no SLO is competitively bound to ASF. If enough f-site antibody were present, no haemagglutination would occur because SLO would not attach to erythrocytes. This would appear to be so with serum 8; haemagglutination was not seen before or after dextran precipitation. Sera 6 and 7 do not appear to have enough f-site antibody to prevent SLO binding to cells.

Absorption of sera with $S L O$-coated erythrocytes at $0^{\circ} \mathrm{C}$. Table III shows results obtained when two high-titre ASO sera (nos 10 and 11) were diluted to contain 256 Todd units of ASO activity and absorbed as detailed in Methods above. Erythrocytes coated with SLO at $0^{\circ} \mathrm{C}$ do not undergo haemolysis because t-site activity is inhibited. Serum ASO titres dropped from 1280 and 640 to 320 and 160 respectively after absorption. These results fit with the concept that (1) t-site antibody is responsible for the original serum titres, (2) that it is adsorbed at $0^{\circ} \mathrm{C}$, and (3) that the residual titre reflects f-site antibody. F-site antibody would be unable to bind to SLO in which the $f$ sites were already bound to membrane cholesterol. Further absorptions of these sera with fresh chilled SLO-coated erythrocytes did not reduce the titres further. Confirmation of the attachment of t-site antibody during the absorption process was obtained from the failure of the absorbing cells to undergo haemolysis when warmed to

TABLE III

Absorption of ASO-positive sera with chilled SLO-coated erythrocytes

\begin{tabular}{|c|c|c|c|c|}
\hline \multirow[b]{2}{*}{$\begin{array}{c}\text { Serum } \\
\text { no. }\end{array}$} & \multicolumn{2}{|c|}{ ASO titre* } & \multicolumn{2}{|c|}{$\begin{array}{l}\text { Percentage haemolysis } \\
\text { of coated cells on } \\
\text { warming to } 37^{\circ} \mathrm{C}\end{array}$} \\
\hline & original & $\begin{array}{c}\text { after } \\
\text { absorption }\end{array}$ & test $†$ & control $\ddagger$ \\
\hline $\begin{array}{l}10 \\
11\end{array}$ & $\begin{array}{r}1280 \\
640\end{array}$ & $\begin{array}{l}320 \\
160\end{array}$ & $\begin{array}{l}0 \\
0\end{array}$ & $\begin{array}{l}100 \\
100\end{array}$ \\
\hline
\end{tabular}

\footnotetext{
* Sera diluted to contain 256 Todd units before absorption. Titres after absorption represent f-site antibody levels after recalculation for the dilution factor.

$\dagger$ Test $=$ SLO-coated cells after absorption of serum at $37^{\circ} \mathrm{C}$.

$\ddagger$ Control $=$ erythrocytes coated with SLO at $0^{\circ} \mathrm{C}$ but not used to absorb serum.
} 
$37^{\circ} \mathrm{C}$. Chilled control SLO-coated cells haemolysed rapidly when warmed to $37^{\circ} \mathrm{C}$ (table III).

Immunofuorescence studies. T-site antibodies in sera with little or no f-site antibody will bind to SLO molecules and the latter will bind to cells because the f-sites are free. In theory such cells might show positive immunofluorescence with antihuman globulin conjugates. Of 20 sera tested, only one with an ASO titre of 320 showed moderate fluorescence.

\section{Presence of $f$-site antibody}

False-positive and-negative latex tests. Table IV shows the results obtained with four sera (nos 15-18) that gave a positive SLO-latex test but had titres of $<200$ Todd units in the haemolytic ASO test after absorption with dextran sulphate, and three sera (nos. 19-21) with a negative SLO-latex test but ASO titres exceeding 200 Todd units after absorption.

False positive tests can be explained as follows. In stage 1 of the latex test, ASF will bind almost instantaneously to free f sites of SLO molecules. Because SLO has a mol. wt of c. 88000 and ASF active peptides have mol. wts between 25000 and 100000 (Watson and Kerr, 1976), we postulate that binding of ASF to SLO f sites results in steric hindrance that precludes $t$-site antibody from attaching to SLO $t$ sites. Consequently, if SLO molecules are attached randomly to latex particles by either for $t$ sites, a sufficient number of $t$ sites will be exposed on the particles to bind $t$-site antibody. Agglutination will, therefore, be by t-site antibody that has failed to attach to SLO in stage 1 of the test. ASF will not be able to exert steric hindrance in stage 2 because the f sites are blocked by attachment to the latex. Attachment of SLO may of course be by sites other than $t$ or $f$, but if the attachment site is close enough to the $f$ site ASF is unlikely to be able to bind and such molecules would also have free $t$ sites available. The fact that the false-positive latex-test results were converted to negative by absorption with dextran sulphate (table IV) supports this interpretation of their cause.

False negative latex tests would arise if sera had antistreptolysin activity due to both ASF and f-site antibody but no t-site antibody was present. In both stages 1 and 2,

\section{TABLE IV}

False positive and false negative SLO-latex tests

\begin{tabular}{|c|c|c|c|c|}
\hline \multirow{2}{*}{$\begin{array}{c}\text { Serum } \\
\text { no. }\end{array}$} & \multicolumn{2}{|c|}{ SLO-latex test } & \multicolumn{2}{|c|}{$\begin{array}{c}\text { Titre in standard } \\
\text { haemolytic ASO test }\end{array}$} \\
\hline & A & B & A & B \\
\hline $\begin{array}{l}15 \\
16 \\
17 \\
18 \\
19 \\
20 \\
21\end{array}$ & $\begin{array}{l}+ \\
+ \\
+ \\
+ \\
- \\
-\end{array}$ & $\begin{array}{l}- \\
- \\
- \\
- \\
+ \\
+ \\
+\end{array}$ & $\begin{array}{l}1280 \\
1280 \\
2560 \\
2560 \\
2560 \\
2560 \\
2560\end{array}$ & $\begin{array}{r}80 \\
160 \\
40 \\
40 \\
640 \\
640 \\
1280\end{array}$ \\
\hline
\end{tabular}

$\mathrm{A}=$ before precipitation with dextran sulphate.

$\mathrm{B}=$ after precipitation with dextran sulphate. 
ASF would compete successfully with $\mathrm{f}$-site antibodies for $\mathrm{f}$-sites so that in stage $2 \mathrm{f}$-site antibody would not be able to bind to sites already occupied. Removal of ASF with dextran sulphate converted the false-negative test to a true positive result (table IV). High-titre preparations of ASF, prepared as described in Materials and methods, did not agglutinate SLO-latex.

The failure of unhaemolysed cells in the standard haemolytic test to show immunofluorescence (see above) may provide indirect evidence of f-site antibody. This would occur if enough f-site antibody were available to bind all SLO molecules so that none was available to bind to added erythrocytes. Similarly, the absorption of high-titre ASO sera with SLO-coated chilled erythrocytes left residual antibody that could not be removed by further absorptions (table III). This would appear to be strong evidence that the residual antibody had specificity for the attachment site of SLO or an antigenic determinant site close enough to cause steric hindrance.

\section{DisCUSSION}

Non-antibody inhibition of SLO due to altered lipoproteins occurs in some sera of jaundiced patients (Packalen, 1948), in hypercholesterolaemia (Winblad, 1965; Watson, Rose and Kerr, 1972), and in some patients with rheumatoid arthritis, as well as in sera contaminated with Staphylococcus aureus or Pseudomonas species (Watson and Kerr, 1976). Thiol agents and oxidation inhibit $\mathrm{f}$-site attachment to erythrocyte membranes (Alouf and Raynaud, 1968) as do cholesterol and some related sterols (Watson and Kerr, 1974). The haemolytically active $t$ site is $\mathrm{SH}$-independent but temperature dependent. The theoretical presence of antibodies with different site specificities has been postulated from the observation that greater amounts of antibody are required to neutralise cell-bound than free SLO and also that the ratio of antibody to bound toxin required for neutralisation varies with different antisera. Because SLO has a mol. wt of 88000 , the existence of different epitopes is not surprising and the presence of antibodies with $\mathrm{f}$-site and $\mathrm{t}$-site specificities may have an additive effect in preventing the cardiotoxicity and other cell toxicities ascribed to the toxin. However, it is still not clear whether $t$ sites play a comparable role on cells other than erythrocytes.

In defining the presence of both types of antibody, particularly clear cut results were obtained with sera absorbed with chilled SLO-coated cells. In this model, f sites are already blocked and the evidence is strong that (a) residual antibody after absorption has f-site specificity, and (b) that absorbed antibody binds to $t$ sites.

Immunofluorescence tests showed the presence of immunoglobulins on unhaemolysed cells from standard haemolytic ASO tests on only one of the 20 sera studied. Haemoglobin has some quenching effect on fluorescence but this is easily overcome by preparing very thin films. Two explanations of this finding may be advanced. (1) Most sera are likely to contain antibodies of both specificities; therefore the only SLO molecules capable of attachment to cells would be those not already bound to $\mathrm{f}$-site antibody. (2) It has been shown that only about 1500 molecules of SLO are capable of attaching to each erythrocyte at full saturation, occupying only about $10^{-3}$ of the total surface area of the cell (Alouf and Raynaud, 1968). Consequently, even with a serum containing only t-site antibody, poor immunofluorescence is likely. Studies are in progress to see whether t-site antibody may be assayed by haemagglutination of cells 
coated with toxoided SLO, since the latter will attach via $f$ sites but not cause haemolysis.

Both false-positive and -negative latex-ASO results have been experienced by laboratories using this test but no clear explanation of them has previously been offered. The experimental findings reported here seem to elucidate the basis of these phenomena.

Most clinical laboratories assaying antistreptolysin activity in sera do not distinguish between ASO and ASF activity. However, even in infections due to Str. pyogenes it can be shown that the serum titre usually represents ASF rather than ASO activity and that titres of the latter are lower, as shown by retitration after precipitation of $\beta$ lipoproteins with dextran sulphate. Winblad (1966), for example, found that the mean levels attributable to lipoprotein activity in 124 such patients was 500 Todd units, whereas the corresponding ASO titres gave a mean value of only 300 units. Our own experience is similar; in patients with streptococcal infection, we believe SLO combines with low levels of ASF present in serum as a result of the normal catabolic turnover of $\beta$ lipoproteins and this stimulates a feedback mechanism that activates endogenous cholesterol esterase, and probably proteolytic enzymes, resulting in an increased production of ASF active peptides. Thus, ASF acts as an early defence mechanism against all the oxygen-labile haemolysins similar to streptolysin $\mathrm{O}$, a mechanism that comes into play before antibody formation can get under way (Watson and Kerr, 1975).

\section{REFERENCES}

Alouf J E, Raynaud M 1968 Some aspects of the mechanisms of lysis of rabbit erythrocytes by streptolysin O. In: Caravano R (ed) Current research on group A streptococcus. Exerpta Medica Foundation, Amsterdam pp 192-206.

Burstein M, Samaille J 1958 Sur une nouvelle méthode de dosage du cholestérol lié aux $\alpha$ et aux $\beta$-lipoprotéines du sérum. Clinica Chimica Acta 3:320-327.

Packalen T 1948 Nonspecific antistreptolysin reactions and serum (or pleural-exudate) cholesterol. Journal of Bacteriology 56:143-156.

Rantz L A, Randall E 1945 A modification of the technic for determination of the antistreptolysin titer. Proceedings of Society of Experimental Biology and Medicine 59:22-25.

Watson K C, Kerr E J C 1974 Sterol structural requirements for inhibition of streptolysin O activity. Biochemical Journal 140:95-98.

Watson K C, Kerr E J C 1975 Functional role of cholesterol in infection and autoimmunity. Lancet 1:308-310.

Watson K C, Kerr E J C 1976 Studies on antistreptolysin O activity generated in serum by microorganisms. British Journal of Experimental Pathology 57:105-113.

Watson K C, Rose T P, Kerr E J C 1972 Some factors influencing the effect of cholesterol on streptolysin O activity. Journal of Clinical Pathology 25:885-891.

Winblad S 1966 Studies on non-specific antistreptolysin $O$ titre 1. The influence of serum $\beta$-lipoproteins on the non-specific antistreptolysin O titre. Acta Pathologica et Microbiologica Scandinavica 66:93-104. 